\title{
Influence of Environmentally Friendly and High-Efficiency Composite Additives on Pulverized Coal Combustion in Cement Industry
}

\author{
Zhiyong Wang, Shijie Wang, ${ }^{1}$ Qi Zhang, ${ }^{1}$ Qingyan Fang, ${ }^{2}$ and Wangsheng Chen ${ }^{3}$ \\ ${ }^{1}$ Hubei Key Laboratory of Coal Conversion and New Carbon Materials, Wuhan University of Science and Technology, \\ Wuhan 430081, China \\ ${ }^{2}$ State Key Laboratory of Coal Combustion, Huazhong University of Science and Technology, Wuhan 430074, China \\ ${ }^{3}$ School of Resource and Environmental Engineering, Wuhan University of Science and Technology, Wuhan 430081, China
}

Correspondence should be addressed to Shijie Wang; shijie_wang@163.com

Received 17 January 2016; Revised 5 March 2016; Accepted 21 March 2016

Academic Editor: Dimitrios C. Rakopoulos

Copyright (C) 2016 Zhiyong Wang et al. This is an open access article distributed under the Creative Commons Attribution License, which permits unrestricted use, distribution, and reproduction in any medium, provided the original work is properly cited.

\begin{abstract}
4 kinds of chemical reagents and 3 kinds of industrial wastes were selected as burning additives for 2 kinds of coals in cement industry. The work focused on the replacement of partial chemical reagents by industrial wastes, which not only reduced the cost and took full advantage of industrial wastes, but also guaranteed the high combustion efficiency and removed the $\mathrm{NO}_{X}$ and $\mathrm{SO}_{2}$ simultaneously. The experiments were carried out in DTF. The combustion residues were analyzed by SEM and XRD. The results showed that the burnout rate was increased after adding the additives; meanwhile, the $\mathrm{NO}_{X}$ and $\mathrm{SO}_{2}$ release concentration were reduced, but the degree of action varied for different additives and coals. The substitute of chemical reagents by industrial wastes was very effective; overall, the cold-rolled iron oxide worked better than others; the particles surface was tougher and the peaks of crystalline phase were lower than raw coal, which indicated that the additives played good roles in combustion process.
\end{abstract}

\section{Introduction}

Coal is widely used in the cement industry. Most of cement factories utilize high-quality coals as flues so that highquality coals are becoming fewer and fewer. Based on the situation, the cement industry has to utilize inferior coals. However, there are severe defects with inferior coals, such as high ash content, low-calorific value, and easy slagging [1]. Those defects may influence the common cement production seriously, especially in rotary kilns or in precalcined kilns [2]. Additionally, the new exhaust standards of air pollutant for cement industry (GB4915-2013) stipulate that the emission concentration of $\mathrm{NO}_{X}$ and $\mathrm{SO}_{2}$ in the current cement industry cannot surpass $400 \mathrm{mg} / \mathrm{Nm}^{3}$ and $200 \mathrm{mg} / \mathrm{Nm}^{3}$ which are half of the previous emission concentration.

In summary, the cement industry is faced with enormous challenge. In order to achieve the sustainable development of cement industry, inferior coals should be utilized effectively and sufficiently. Without changing the original cement industry devices, adding coal burning additives is the effective way to promote the combustion of inferior coals and meet the pollution emission requirement of GB4915-2013. In recent years, many investigators had used chemical reagents as coal burning additives [3-8]. Although those chemical reagents could promote inferior coal combustion significantly, some of them were costly, such as $\mathrm{CeO}_{2}$ and $\mathrm{La}_{2} \mathrm{O}_{3}$. Then, some investigators used industrial wastes coal as coal burning additives. Zhou and Li [9] and Wu et al. [10] found industrial wastes could promote the coal combustion, but the efficiency was less than chemical reagents. Though the investigators had made great achievements in coal burning additives, these findings were almost used in the boilers and the electricity generation. It was well known that the principle and the process of different industrial varied, so these additives were not completely suitable for the cement industry. He et al. [1] and Xie and He [11] had researched some chemical additives 
TABLE 1: Ultimate and proximate analysis (wt.\%) of coal samples.

\begin{tabular}{lccccccccrr}
\hline \multirow{2}{*}{ Number } & \multicolumn{4}{c}{ Ultimate analysis, ad. } & \multicolumn{4}{c}{ Proximate analysis, ad. } \\
& $\mathrm{C}$ & $\mathrm{H}$ & $\mathrm{O}$ & $\mathrm{N}$ & $\mathrm{S}$ & Moisture & Ash & Volatile & Fixed carbon \\
\hline $\mathrm{C} 1$ & 59.91 & 1.22 & 4.56 & 0.94 & 0.25 & 3.90 & 29.22 & 7.66 & 59.23 & 14.45 \\
$\mathrm{C} 2$ & 28.55 & 0.20 & 6.10 & 0.79 & 1.16 & 2.17 & 61.03 & 9.86 & 27.02 & 29.94 \\
\hline
\end{tabular}

TABLe 2: Chemical composition of industrial wastes (wt.\%).

\begin{tabular}{lcccccccccccc}
\hline Number & $\mathrm{Na}_{2} \mathrm{O}$ & $\mathrm{MgO}$ & $\mathrm{Al}_{2} \mathrm{O}_{3}$ & $\mathrm{SiO}_{2}$ & $\mathrm{P}_{2} \mathrm{O}_{5}$ & $\mathrm{SO}_{3}$ & $\mathrm{Cl}_{2} \mathrm{O}$ & $\mathrm{K}_{2} \mathrm{O}$ & $\mathrm{CaO}$ & $\mathrm{TiO}_{2}$ & $\mathrm{MnO}_{2} \mathrm{Fe}_{2} \mathrm{O}_{3}$ \\
\hline $\mathrm{A} 1$ & 0.95 & 3.35 & 15.05 & 16.92 & 1.71 & 5.33 & 0.73 & 0.12 & 47.83 & 0.40 & 0.45 & 7.21 \\
$\mathrm{~A} 2$ & 3.46 & 3.98 & 4.07 & 12.47 & 0.70 & 6.90 & 1.01 & 0.21 & 25.34 & 0.93 & 0.73 & 42.30 \\
$\mathrm{~A} 3$ & - & 0.76 & 1.45 & 0.72 & 0.09 & 0.25 & 0.71 & 0.04 & 0.05 & 0.17 & 0.31 & 95.45 \\
\hline
\end{tabular}

which were used in cement industry; however, they only researched the catalytic combustion effect of the additives and did not research the effect on reducing the release of the $\mathrm{NO}_{X}$ and $\mathrm{SO}_{2}$ simultaneously. Thus, in current background, it was significant to exploit the additives for cement industry which could promote the combustion and reduce the release of the $\mathrm{NO}_{X}$ and $\mathrm{SO}_{2}$ simultaneously. Therefore, in our work, chemical reagents and industrial wastes were composited as the coal burning additives, and the 3 kinds of industrial wastes were used to replace partial chemical reagents, respectively. The composite additives not only improved the combustion efficiency and saved the cost, but also reduced the release of the $\mathrm{NO}_{X}$ and $\mathrm{SO}_{2}$ and developed a high value-added way to dispose industrial wastes.

\section{Materials and Methods}

2.1. Coal Samples. In current work, two different types of inferior coals were selected for investigation, code-named C1 and C2. The properties of coal samples were listed in Table 1. It was concluded from Table 1 that the $\mathrm{C} 2$ was a high ash coal, and the volatile content of $\mathrm{C} 2$ was higher than $\mathrm{C} 1$. The coal samples were prepared by coning and quartering and were grounded to $150 \mu \mathrm{m}$ according to DTF system.

2.2. Composite Additives. Based on the previous studies of coal burning additives [12, 13], four kinds of chemical reagents and three kinds of industrial wastes were selected as additives in our work. Among them, the chemical reagents $\left(\mathrm{BaCO}_{3}: \mathrm{MnO}_{2}: \mathrm{NaCl}: \mathrm{NaClO}_{4}=1: 1: 2: 2\right)$ were a whole, code-named A. The three kinds of industrial wastes were steel slag (code name: A1), desulfurization slag (code name: A2), and cold-rolled iron oxide (code name: A3). The chemical compositions of industrial wastes were listed in Table 2.

$\mathrm{A} 1, \mathrm{~A} 2$, and $\mathrm{A} 3$ were used to replace partial A, respectively, so the composite additives were $\mathrm{A}+\mathrm{A} 1, \mathrm{~A}+\mathrm{A} 2$, and $\mathrm{A}+\mathrm{A} 3$. The amount of composite additives was $2.0 \%$ relative to the coal samples, and the additive amount of A1, A2, and A3 was $0 \%, 0.2 \%, 0.4 \%, 0.6 \%, 0.8 \%$, and $1.0 \%$, respectively; in other words, the amount of A was $2 \%, 1.8 \%, 1.6 \%, 1.4 \%, 1.2 \%$, and $1.0 \%$. The composite additives were added to the coals by drymixed method according to the above types and proportions. In order to mix equably, the catalytic coal samples were put

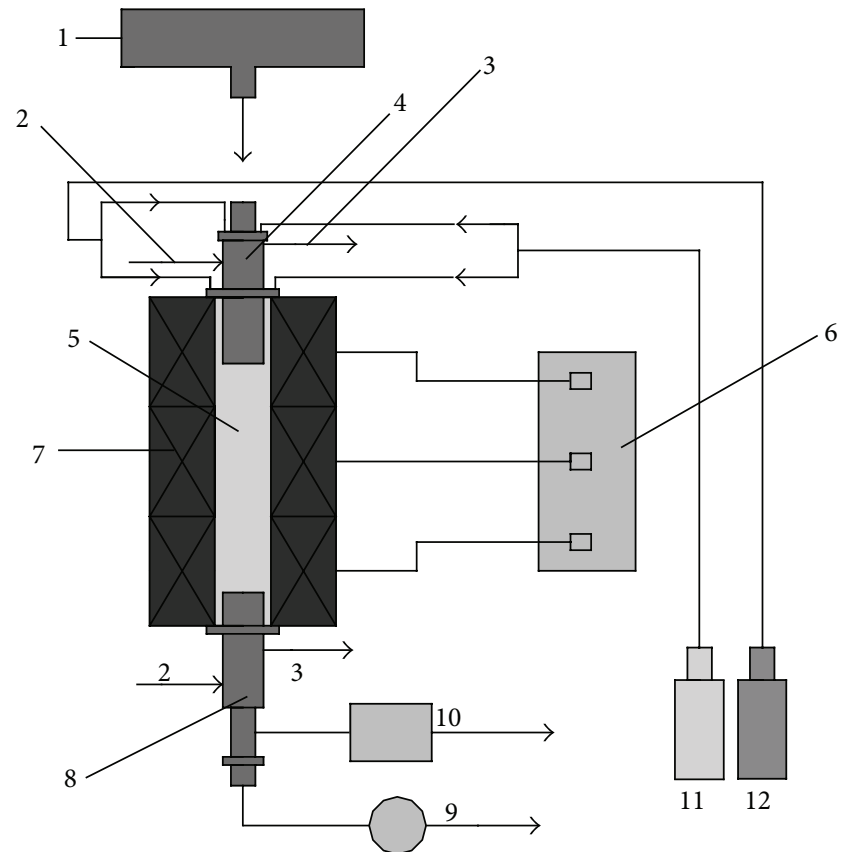
(1) Power feeder
(2) Cooling water inlet
(3) Cooling water outlet
(4) Combustion reactor
(5) Alumina tube
(6) Temperature control cabinet
(7) Silicon carbide code
(9) Pump
(11) Oxygen
(8) Sampling probe
(10) Flue gas analyzer
(12) Nitrogen

FIGURE 1: Schematic of the DTF system.

into the rotary drum for $30 \mathrm{~min}$, and the rotating speed was $20 \mathrm{r} / \mathrm{min}$.

2.3. Experimental System. In our experiment, a drop tube furnace (DTF) was used to simulate the coal catalytic combustion. The DTF experimental system was shown in Figure 1. It included the power feeding, the cooling water, the gas distribution system, the combustion reactor, the temperature control cabinet, the sample collection system, and the gas analyzer. Among them, the amount of power feeding was $0.5 \pm 0.02 \mathrm{~g} / \mathrm{min}$; the gas distribution system simulated air 

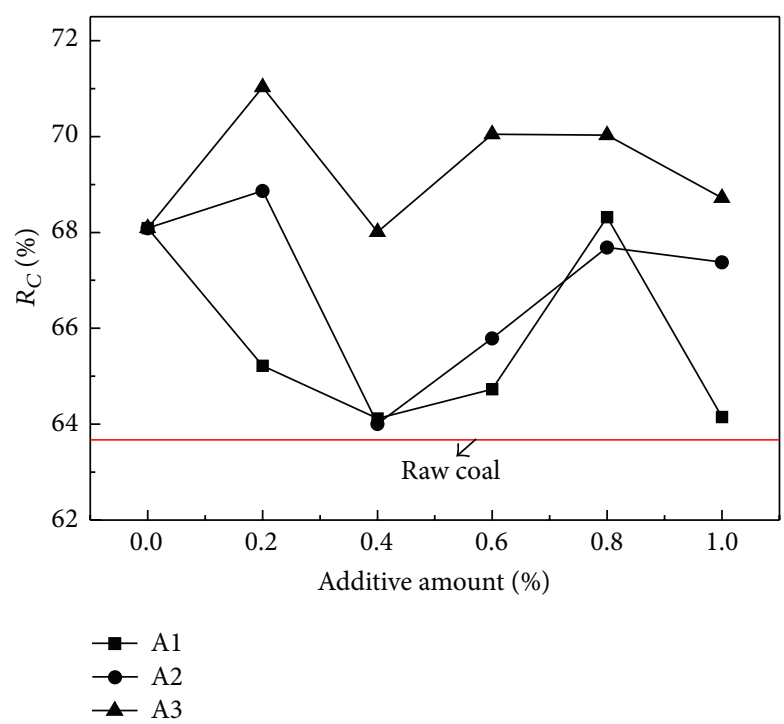

Figure 2: The effect of additive on $R_{C}$ of $\mathrm{Cl}$.

atmosphere, including $\mathrm{O}_{2}: \mathrm{N}_{2}=1: 4$; the combustion reactor was made of an alumina tube with a length of $2.3 \mathrm{~m}$; the temperature was $950^{\circ} \mathrm{C}$ which approached the temperature of the cement decomposing furnace; the gas analyzer was used to detect the concentration of $\mathrm{SO}_{2}$ and $\mathrm{NO}_{X}$; the coal ash was collected by filter cartridge; then, it was sent to muffle furnace for secondary combustion. The burnout rate was calculated by this method, and the burnout rate formula was shown as follows:

$$
R_{C}=\left[1-\frac{A_{0}}{100-A_{0}} \times \frac{100-A_{i}}{A_{i}}\right] \times 100 \% .
$$

In the formula, $A_{0}$ stands for ash contents in the raw coal and $A_{i}$ stands for ash contents in the coal combustion residues.

\section{Results and Discussion}

3.1. Effect of Additives on the Burnout Rate. The burnout rate is an important index during coal combustion. The higher the burnout rate, the better the coal burn. As shown in Figures 2 and 3, the burnout rate was all increased after adding additives, except in $1.0 \% \mathrm{~A}+1.0 \% \mathrm{~A} 1$. It was well known that a lot of alkali metals, alkaline earth metals, transition metal, and their salts existed in the additives, and they acted as intermediates and promoted the diffusion of oxygen to the coal surface in the combustion process, especially $\mathrm{MnO}_{2}$ and $\mathrm{Fe}_{2} \mathrm{O}_{3}$ [2,14]. Take $\mathrm{Fe}_{2} \mathrm{O}_{3}$ as examples; at first, reduction reaction occurred between $\mathrm{Fe}_{2} \mathrm{O}_{3}$ and carbon, and $\mathrm{Fe}_{2} \mathrm{O}_{3}$ was reduced to $\mathrm{FeO}$. Then $\mathrm{FeO}$ was oxidized into $\mathrm{Fe}_{2} \mathrm{O}_{3}$ by oxygen. Next, the above reaction was proceeding once again. The reactions were shown as follows. Therefore,

$$
\begin{gathered}
2 \mathrm{Fe}_{2} \mathrm{O}_{3}+\mathrm{C} \longrightarrow 4 \mathrm{FeO}+\mathrm{CO}_{2} \\
4 \mathrm{FeO}+\mathrm{O}_{2} \longrightarrow 2 \mathrm{Fe}_{2} \mathrm{O}_{3}
\end{gathered}
$$

$\mathrm{Fe}_{2} \mathrm{O}_{3}$ was in the circulating process of oxidation and reduction, which made the carbon surface to contact the oxygen,

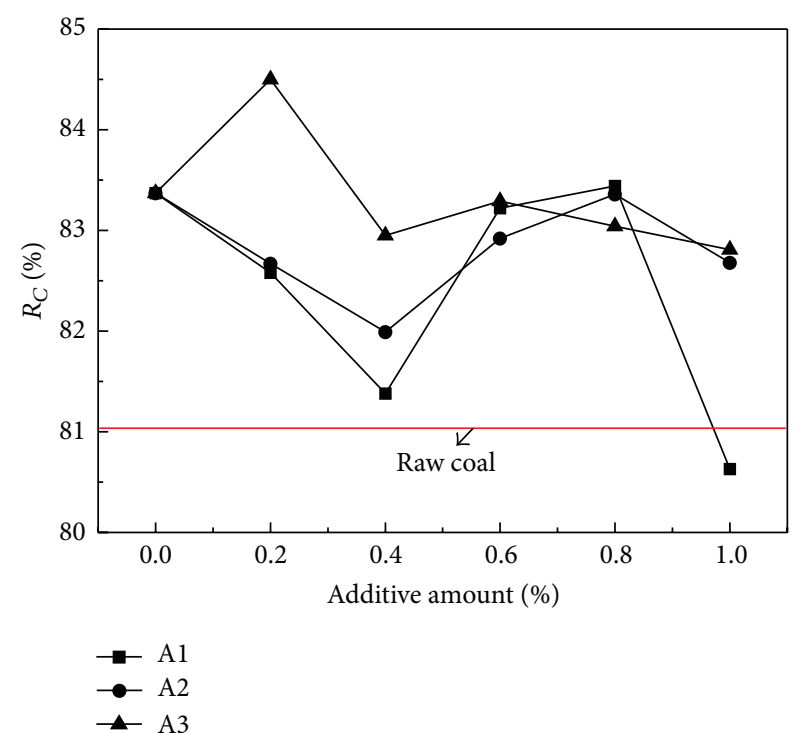

Figure 3: The effect of additive on $R_{C}$ of $\mathrm{C} 2$.

and the combustion of carbon particles was improved [10]. Meanwhile, the $\mathrm{NaClO}_{4}$ could decompose $\mathrm{O}_{2}$ in high temperature, which also promoted the contact between the oxygen and carbon. Besides, the $\mathrm{NaCl}$ made the pulverized coal fluffy, promoting the combustion process further. However, when the addition of $\mathrm{CaO}$ was excessive, the $\mathrm{CaO}$ would sinter. So the pores of coal might be blocked because of the sintering, which would hinder the diffusion of oxygen to the coal surface. Table 2 indicated there was a large amount of $\mathrm{CaO}$ in $\mathrm{A} 1$. Thus, the additives of $1.0 \% \mathrm{~A}+1.0 \% \mathrm{~A} 1 \mathrm{might}$ inhibit the coal combustion. In the view of the burnout rate, $\mathrm{A}$ $+\mathrm{A} 3$ showed a better catalytic effect, because a large amount of $\mathrm{Fe}_{2} \mathrm{O}_{3}$ existed in it. The optimal additive amount of $\mathrm{A} 3$ was $0.2 \%$. It could be seen from Figures 2 and 3 that the burnout rate of different coal varied. The burnout rate in the level of the order was $\mathrm{C} 2>\mathrm{C} 1$, which was an evidence that the higher the volatile content, the bigger the burnout rate. As for $\mathrm{Cl}$, the biggest burnout rate was $71.03 \%$, which was $7.15 \%$ bigger than the raw coal. As for C2, the biggest burnout rate was $84.5 \%$, which was $3.44 \%$ bigger than the raw coal. It was found that the catalytic effect on $\mathrm{C} 1$ was better than $\mathrm{C} 2$. The possible reason was that the $\mathrm{C} 2$ was easier to burn than $\mathrm{C}$, and the catalytic effect for uneasy burned coal was obviously more. It was also concluded from Figures 2 and 3 that when only $\mathrm{A}$ was added to the raw coals $\mathrm{C} 1$ and $\mathrm{C} 2$, the burnout rate was $68.09 \%$ and $83.37 \%$. While industrial wastes were added to replace partial $\mathrm{A}$, the burnout rate improved comparing with pure A, so the replacement of chemical reagents by industrial wastes was feasible.

3.2. Effect of Additives on the $\mathrm{NO}_{X}$ Release Concentration. As shown in Figures 4 and 5, it was found that the release concentration of $\mathrm{NO}_{X}$ after adding coal burning additives was lower than the raw coal, because of the existence of alkaline metals oxides, alkali metal salt, and transitional metal oxide in the additives, such as $\mathrm{NaCl}, \mathrm{MnO}_{2}$, and $\mathrm{Fe}_{2} \mathrm{O}_{3}$. These substances suppressed the conversion of fuel- $\mathrm{N}$ to $\mathrm{NO}_{X}$ [4]. 
TABLE 3: The effect of different additives on denitrification efficiency of $\mathrm{C} 1$ and $\mathrm{C} 2(\%)$.

\begin{tabular}{|c|c|c|c|c|c|c|c|c|}
\hline \multirow{2}{*}{ Type of coal } & \multirow{2}{*}{ Raw coal } & \multirow{2}{*}{ Type of waste } & \multicolumn{6}{|c|}{ Additive amount $/ \%$} \\
\hline & & & 0 & 0.2 & 0.4 & 0.6 & 0.8 & 1.0 \\
\hline \multirow{3}{*}{$\mathrm{C} 1$} & \multirow{3}{*}{0} & $\mathrm{~A} 1$ & 15.04 & 8.23 & 6.81 & 9.13 & 14.40 & 7.46 \\
\hline & & $\mathrm{A} 2$ & 15.04 & 18.38 & 11.83 & 16.84 & 8.10 & 14.40 \\
\hline & & A3 & 15.04 & 19.28 & 13.24 & 17.74 & 16.97 & 15.55 \\
\hline \multirow{3}{*}{$\mathrm{C} 2$} & \multirow{3}{*}{0} & $\mathrm{~A} 1$ & 13.88 & 7.52 & 13.45 & 10.91 & 15.04 & 5.72 \\
\hline & & $\mathrm{A} 2$ & 13.88 & 7.10 & 7.42 & 13.24 & 19.28 & 14.09 \\
\hline & & A3 & 13.88 & 25.32 & 15.47 & 20.44 & 17.06 & 14.51 \\
\hline
\end{tabular}
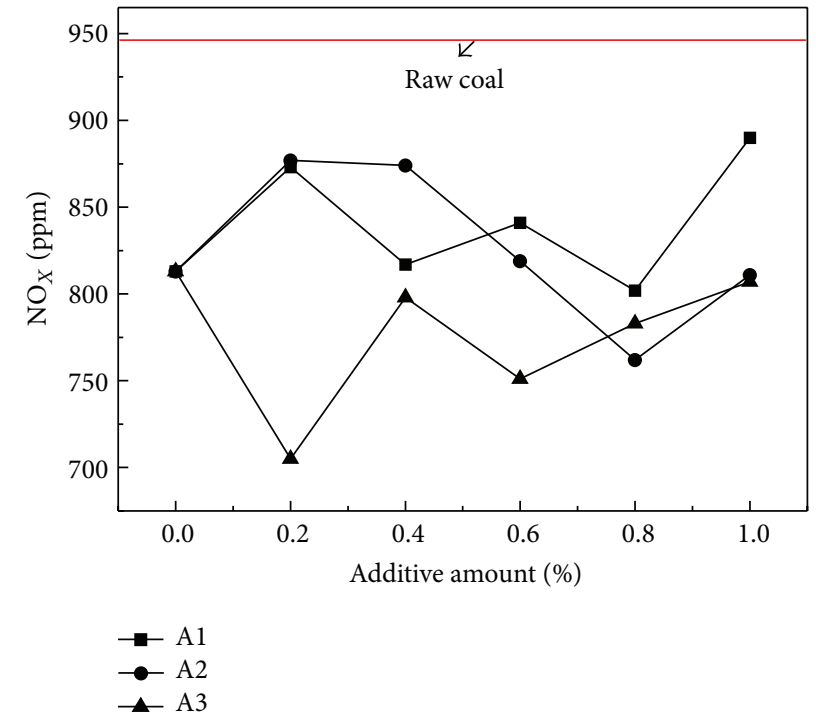

FIGURE 4: The effect of additive on $\mathrm{NO}_{X}$ release concentration of $\mathrm{Cl}$.

Among these three composite additives, $\mathrm{A}+\mathrm{A} 3$ worked best. The reason was that a large amount of $\mathrm{Fe}_{2} \mathrm{O}_{3}$ existed in $\mathrm{A} 3$, and $\mathrm{Fe}_{2} \mathrm{O}_{3}$ could promote the selective catalytic reduction (SCR) activity; besides, it exhibited high thermal stability [15]. It was found that the substitution amount of industrial wastes was not the more the better. As for A3, the optimal additive amount was $0.2 \%$. It also could be seen from Figures 4 and 5 that the $\mathrm{NO}_{X}$ release concentration of different coals varied. The raw coal of $\mathrm{C} 1$ and C2 was 778 ppm and 944 ppm. Though the nitrogen content of $\mathrm{C} 2$ was a litter lower than $\mathrm{C} 1$, the burnout rate of $\mathrm{C} 2$ was higher than $\mathrm{C} 1$ obviously, so the $\mathrm{C} 2$ might generate more $\mathrm{NO}_{X}$ in the combustion process. It was known from Table 3 that the denitrification efficiency was $15.04 \%$ and $13.88 \%$ when only $2.0 \%$ A was added to the $\mathrm{C} 1$ and $\mathrm{C} 2$. However, when $\mathrm{A} 1, \mathrm{~A} 2$, and $\mathrm{A} 3$ were used to replace partial $\mathrm{A}$, the denitrification efficiency of $\mathrm{C} 1$ and $\mathrm{C} 2$ was increased under the certain amount and the highest denitrification efficiency was $19.28 \%$ and $25.32 \%$. In the perspective of denitrification, the best substituendum was A3 and the best instead proportion was $0.2 \%$.

3.3. Effect of Additives on the $\mathrm{SO}_{2}$ Release Concentration. A comparison of the $\mathrm{C} 1$ and the $\mathrm{C} 2$ with or without additives on the $\mathrm{SO}_{2}$ release concentration was shown in Figures 6 and 7. These two figures showed that the additives could reduce the

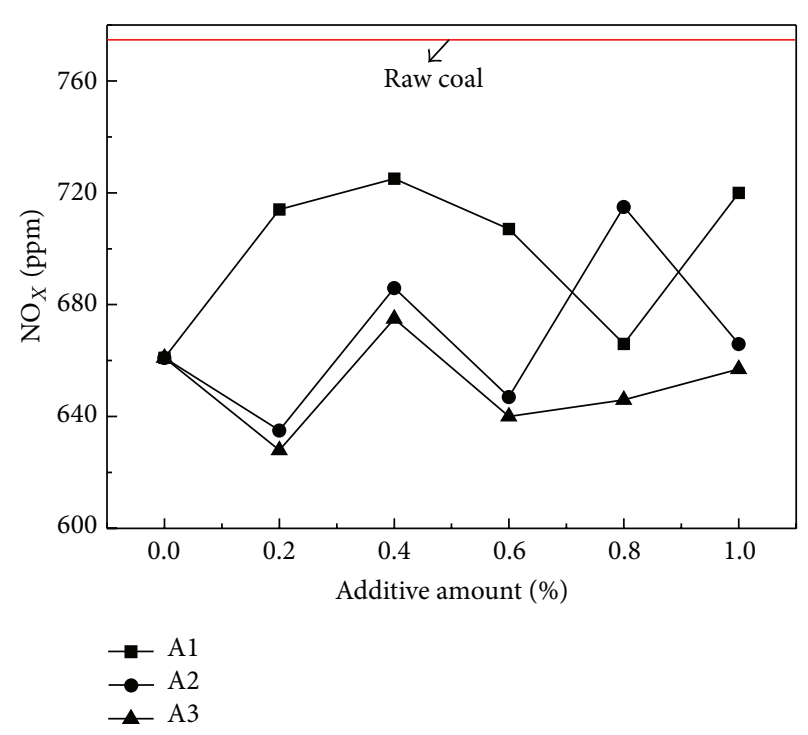

FIGURE 5: The effect of additive on $\mathrm{NO}_{X}$ release concentration of $\mathrm{C} 2$.

release concentration of $\mathrm{SO}_{2}$. From the overall trend, $\mathrm{A}+$ Al showed the best effect on reducing the release of $\mathrm{SO}_{2}$. The reason was that $47.83 \% \mathrm{CaO}$ existed in A1 (Table 2), and the reaction (4) happened as follows [16]. Therefore, A + A1 worked best

$$
\mathrm{CaO}+\mathrm{SO}_{2}+\frac{1}{2 \mathrm{O}_{2}} \longrightarrow \mathrm{CaSO}_{4}
$$

$\mathrm{A}+\mathrm{A} 2$ worked better than $\mathrm{A}+\mathrm{A} 3$. It was concluded that the $\mathrm{SO}_{2}$ release concentration was lowest when the additive amount of A1 was $0.8 \%$. It was also known from Figures 6 and 7 that the $\mathrm{SO}_{2}$ release concentration of $\mathrm{C} 2$ raw coal was much higher than $\mathrm{C} 1$ raw coal, because the sulfur content of $\mathrm{C} 2$ was higher than $\mathrm{C} 1$ (Table 1). Besides, the burnout rate of $\mathrm{C} 2$ was higher than $\mathrm{C} 1$ too. In Table 4, when only A was added to the raw coal, the desulfurization efficiency of $\mathrm{C} 1$ and $\mathrm{C} 2$ was $4.42 \%$ and $8.17 \%$. The possible reason was that reaction (5) happened [7]. In addition, $\mathrm{NaCl}$ could enhance the sulfur retention capacity of coal ash

$$
2 \mathrm{BaCO}_{3}+2 \mathrm{SO}_{2}+\mathrm{O}_{2} \longrightarrow 2 \mathrm{BaSO}_{4}+2 \mathrm{CO}_{2}
$$

and then decrease $\mathrm{SO}_{2}$ release concentration [7]. It also could be seen from Table 4 that the optimal additive was $1.2 \% \mathrm{~A}$ $+0.8 \% \mathrm{~A} 1$ and the highest desulfurization efficiency of $\mathrm{Cl}$ 
TABLE 4: The effect of different additives on desulfurization efficiency of $\mathrm{C} 1$ and $\mathrm{C} 2$ (\%).

\begin{tabular}{|c|c|c|c|c|c|c|c|c|}
\hline \multirow{2}{*}{ Type of coal } & \multirow{2}{*}{ Raw coal } & \multirow{2}{*}{ Type of waste } & \multicolumn{6}{|c|}{ Additive amount $/ \%$} \\
\hline & & & 0 & 0.2 & 0.4 & 0.6 & 0.8 & 1.0 \\
\hline \multirow{3}{*}{$\mathrm{C} 1$} & \multirow{3}{*}{0} & $\mathrm{~A} 1$ & 4.42 & 25.22 & 17.26 & 21.24 & 30.97 & 19.51 \\
\hline & & A2 & 4.42 & 20.80 & 15.93 & 17.26 & 18.58 & 19.37 \\
\hline & & $\mathrm{A} 3$ & 4.42 & 16.37 & 8.41 & 14.60 & 13.72 & 11.06 \\
\hline \multirow{3}{*}{$\mathrm{C} 2$} & \multirow{3}{*}{0} & $\mathrm{~A} 1$ & 8.17 & 10.04 & 11.60 & 14.43 & 20.05 & 9.41 \\
\hline & & $\mathrm{A} 2$ & 8.17 & 11.88 & 10.16 & 12.08 & 14.03 & 12.28 \\
\hline & & $\mathrm{A} 3$ & 8.17 & 11.64 & 9.29 & 10.24 & 9.88 & 8.53 \\
\hline
\end{tabular}

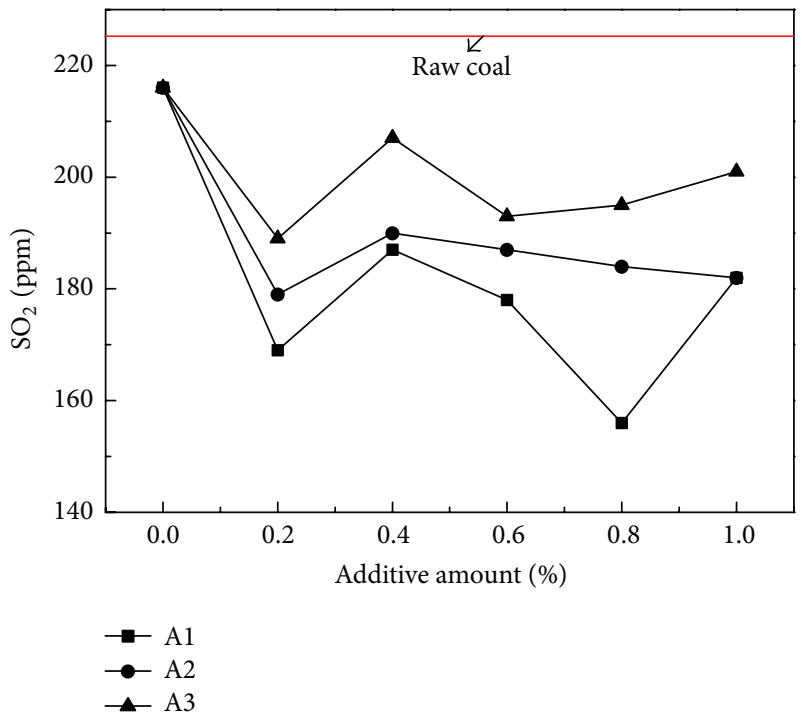

FIgure 6: The effect of additive on $\mathrm{SO}_{2}$ release concentration of $\mathrm{C}$.

and C2 was $30.97 \%$ and $20.05 \%$. With regard to the same additive and additive amount, the desulfurization efficiency of different coal varied.

3.4. The SEM of Combustion Residue. The combustion residue of $\mathrm{C} 1$ raw coal and $\mathrm{C} 1$ with $1.8 \% \mathrm{~A}+0.2 \% \mathrm{~A} 3$ was analyzed by the scanning electron microscopy (SEM) and the $\mathrm{X}$-ray diffraction (XRD). SEM is often used to observe the surface morphology of the coal. Besides, the pore structure and the three-dimensional structure are observed intuitively. In our work, SEM was used to deduce the microstructure of different sample, and the micrographs were included in Figure 8. As shown in Figure 8, the surface morphology of coal surface was changed after adding the additive. From Figure 8(a), it could be seen that the particles surface was smooth relatively except for some small holes, and partial sintering phenomena existed. Figure 8 (b) showed that the combustion of carbon particles was aggravated, and the particles surface was very tough and looked like a loose honeycomb, only leaving framework. Comparing Figures 8 (a) and $8(\mathrm{~b})$, it was concluded that the additive of $1.8 \% \mathrm{~A}+$ $0.2 \%$ A 3 could promote the combustion process of pulverized coal commendably. It was because there were a lot of alkaline metals oxides, alkali metal salt, and transitional metal oxide

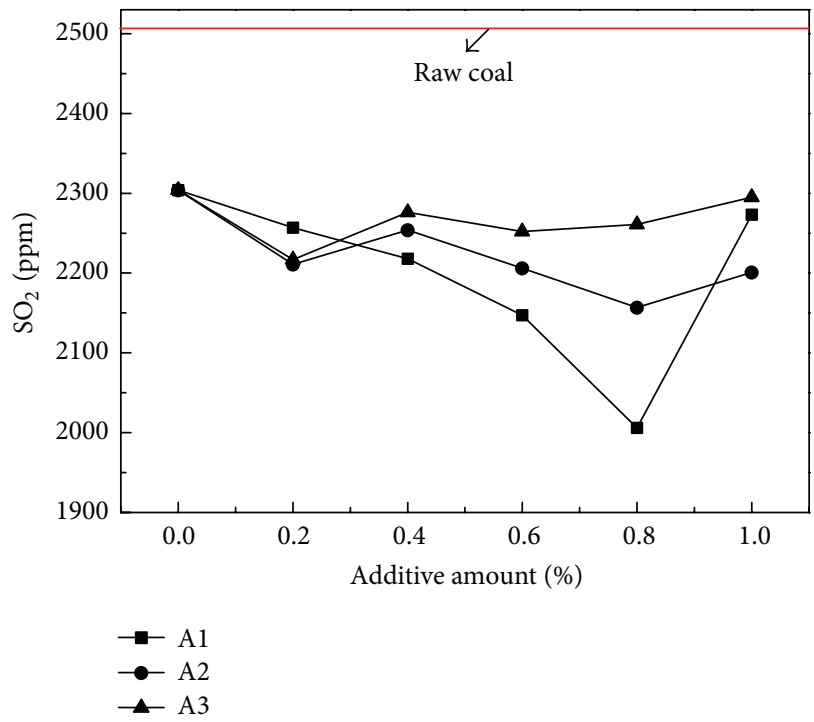

FIgURE 7: The effect of additive on $\mathrm{SO}_{2}$ release concentration of $\mathrm{C} 2$.

existing in the additives, such as $\mathrm{MnO}_{2}, \mathrm{NaCl}, \mathrm{NaClO}_{4}$, and $\mathrm{Fe}_{2} \mathrm{O}_{3}$. These substances promoted the contact between the oxygen and carbon.

3.5. The XRD of Combustion Residue. X-ray diffraction (XRD) is an effective means to study the solid structure, and it offers particular advantages in identifying various kinds of mineral forms that relate to structural damage. In our work, XRD was used to reveal the structural changes of coals with or without additives. The XRD of combustion residues was represented in Figure 9. It was shown from Figure 9 that the diffraction pattern changed slightly after adding additives comparing to the raw coals. The main crystalline phases of raw coal were silicon dioxide and aluminum silicon oxide. When $1.8 \% \mathrm{~A}+0.2 \% \mathrm{~A} 3$ were added to the raw coal, a new crystalline phase appeared. The possible reason was that the additives participated in the coal combustion reaction and generated a new compound. It also could be seen that the peaks of raw coal with additives were lower than the raw coal. As was known from Wang et al. [12], the lower peak of crystalline phase indicated that the samples burned more completely. Thus, from the X-ray diffraction, it was also concluded that the additives promoted the coal combustion. 


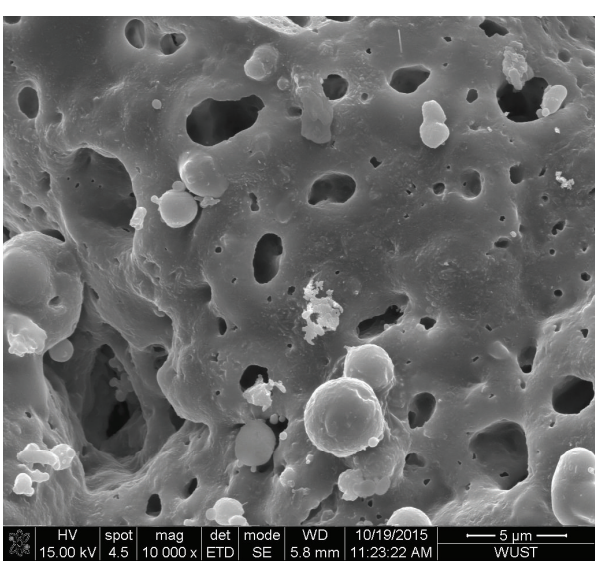

(a) Residue of raw coal combustion

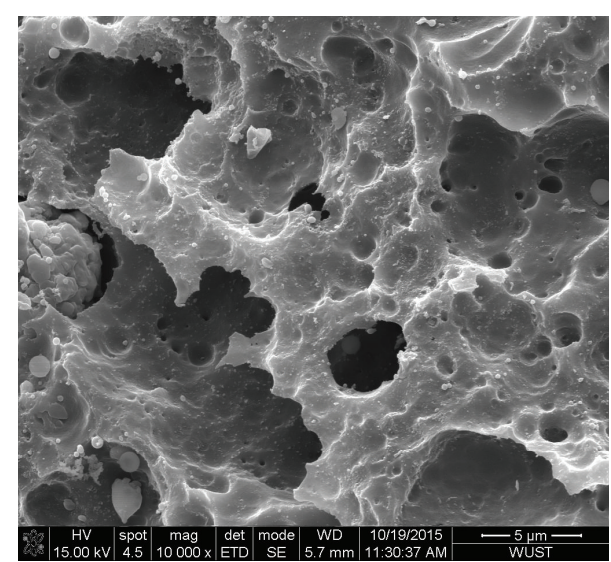

(b) Residue of raw coal combustion $1.8 \% \mathrm{~A}+0.2 \% \mathrm{~A} 3$

FIgURE 8: The SEM images of coal combustion residues.
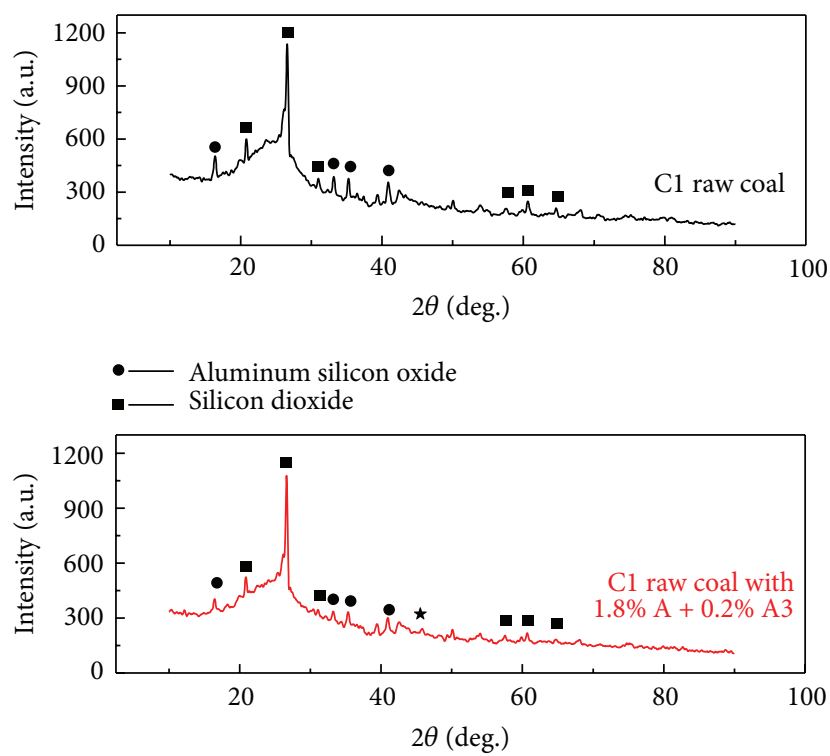

- - Aluminum silicon oxide

- Silicon dioxide

$\star$ — Iron nitride

FIGURE 9: The XRD of combustion residue.

\section{Conclusions}

(1) The burnout rate of different coals varied. The burnout rate was all increased after adding additives, except in $1.0 \% \mathrm{~A}+1.0 \% \mathrm{~A} 1$. It was concluded that the cold-rolled iron oxide worked best, and the optimal substituted amount was $0.2 \%$.

(2) For $\mathrm{NO}_{X}$ release concentration, different coals varied. When steel slags, desulfurization slag and cold-rolled iron oxide were used to replace chemical reagents, respectively; the release concentration of $\mathrm{NO}_{X}$ was all reduced. The cold-rolled iron oxide worked better than others, and the optimal substituted amount was $0.2 \%$.
(3) For $\mathrm{SO}_{2}$ release concentration, different coals varied greatly. The substitute by industrial wastes also showed a good effect. Among these three industrial wastes, the steel slag had the best desulfurization effect, and the optimal substituted amount was $0.8 \%$.

(4) The SEM results showed the particles surface was very tough and looked like loose honeycomb after adding the additives. The XRD results showed that the diffraction pattern after adding the additives changed slightly compared to the raw coals, and the peaks were lower than raw coal. The analysis results indicated that the additives played good roles in combustion process.

In conclusion, $1.8 \% \mathrm{~A}+0.2 \% \mathrm{~A} 3$ was selected as the optimum additive for the cement industry in our work, which could reduce the release of the $\mathrm{NO}_{X}$ and $\mathrm{SO}_{2}$ and promoted the combustion simultaneously.

\section{Competing Interests}

The authors declare that there are no competing interests regarding the publication of this paper.

\section{Acknowledgments}

The authors are grateful for the support provided by the Foundation of State Key Laboratory of Coal Combustion (Grant no. FSKLCC1412) and also appreciate the support provided by the National Natural Science Fund Project (Grant no. 51476118).

\section{References}

[1] X.-M. He, J. Qin, R.-Z. Liu et al., "Catalytic combustion of inferior coal in the cement industry by thermogravimetric analysis," Energy Sources, Part A: Recovery, Utilization and Environmental Effects, vol. 35, no. 13, pp. 1233-1240, 2013. 
[2] B.-G. Ma, X.-G. Li, L. Xu, K. Wang, and X.-G. Wang, "Investigation on catalyzed combustion of high ash coal by thermogravimetric analysis," Thermochimica Acta, vol. 445, no. 1, pp. 19-22, 2006.

[3] K. Yin, Y.-M. Zhou, Q.-Z. Yao, C. Fang, and Z.-W. Zhang, "Thermogravimetric analysis of the catalytic effect of metallic compounds on the combustion behaviors of coals," Reaction Kinetics, Mechanisms and Catalysis, vol. 106, no. 2, pp. 369-377, 2012.

[4] M.-Y. Yao and D.-F. Che, "Catalytic effects of minerals on $\mathrm{NO}_{\mathrm{x}}$ emission from coal combustion," Energy Sources, Part A: Recovery, Utilization and Environmental Effects, vol. 29, no. 11, pp. 1005-1016, 2007.

[5] X.-Z. Gong, Z.-C. Guo, and Z. Wang, "Reactivity of pulverized coals during combustion catalyzed by $\mathrm{CeO}_{2}$ and $\mathrm{Fe}_{2} \mathrm{O}_{3}$," Combustion and Flame, vol. 157, no. 2, pp. 351-356, 2010.

[6] Y. Xu and B.-S. Hu, "Influence of $\mathrm{CeO}_{2}$ and $\mathrm{La}_{2} \mathrm{O}_{3}$ as additives on burning process of pulverized coal injection into blast furnace," Chinese Rare Earths, vol. 26, no. 2, pp. 56-58, 2005.

[7] Y.-H. Liu, D.-F. Che, and T.-M. Xu, "Catalytic reduction of $\mathrm{SO}_{2}$ during combustion of typical Chinese coals," Fuel Processing Technology, vol. 79, no. 2, pp. 157-169, 2002.

[8] X.-Z. Gong, Z.-C. Guo, and Z. Wang, "Effect of $\mathrm{K}_{2} \mathrm{CO}_{3}$ and $\mathrm{Fe}_{2} \mathrm{O}_{3}$ on combustion reactivity of pulverized coal by thermogravimetry analysis," Journal of Fuel Chemistry and Technology, vol. 37, no. 1, pp. 42-48, 2009.

[9] L.-C. Zhou and C.-Y. Li, "Effect of industrial waste on combustion property of anthracite," Iron and Steel, vol. 49, no. 6, pp. 91-96, 2014.

[10] F. Wu, S.-J. Wang, G. Zhang et al., "Influence of steel industrial wastes on burnout rate and $\mathrm{NO}_{x}$ release during the pulverized coal catalytic combustion," Journal of the Energy Institute, vol. 87, no. 2, pp. 134-139, 2014.

[11] J.-L. Xie and F. He, "Catalyzed combustion study of anthracite in cement kiln," Journal of the Chinese Ceramic Society, vol. 26, no. 6, pp. 192-195, 1998.

[12] S.-J. Wang, J. Qin, J.-G. Wang, X.-M. He, and C.-J. Huang, "The effect of catalysts on combustion characteristics of inferior coal," Energy Sources, Part A: Recovery, Utilization and Environmental Effects, vol. 35, no. 20, pp. 1914-1920, 2013.

[13] C.-J. Huang, S.-J. Wang, F. Wu, P. Zhu, Z.-H. Zhou, and J.-M. Yi, "The effect of waste slag of the steel industry on pulverized coal combustion," Energy Sources, Part A: Recovery, Utilization and Environmental Effects, vol. 35, no. 20, pp. 1891-1897, 2013.

[14] D. Vamvuka, V. Tsamourgeli, and M. Galetakis, "Study on catalytic combustion of biomass mixtures with poor coals," Combustion Science and Technology, vol. 186, no. 1, pp. 68-82, 2014.

[15] K. Yamazaki, N. Takahashi, H. Shinjoh, and M. Sugiura, "The performance of $\mathrm{NO}_{x}$ storage-reduction catalyst containing Fecompound after thermal aging," Applied Catalysis B: Environmental, vol. 53, no. 1, pp. 1-12, 2004.

[16] L. Zhang, B. Zhang, Z. Yang, and M. Guo, "The role of water on the performance of calcium oxide-based sorbents for carbon dioxide capture: a review," Energy Technology, vol. 3, no. 1, pp. 10-19, 2015. 


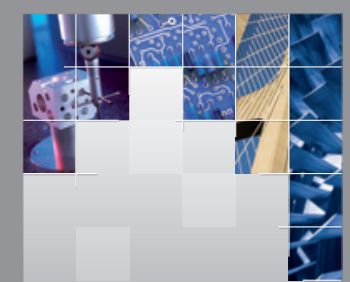

\section{Enfincering}
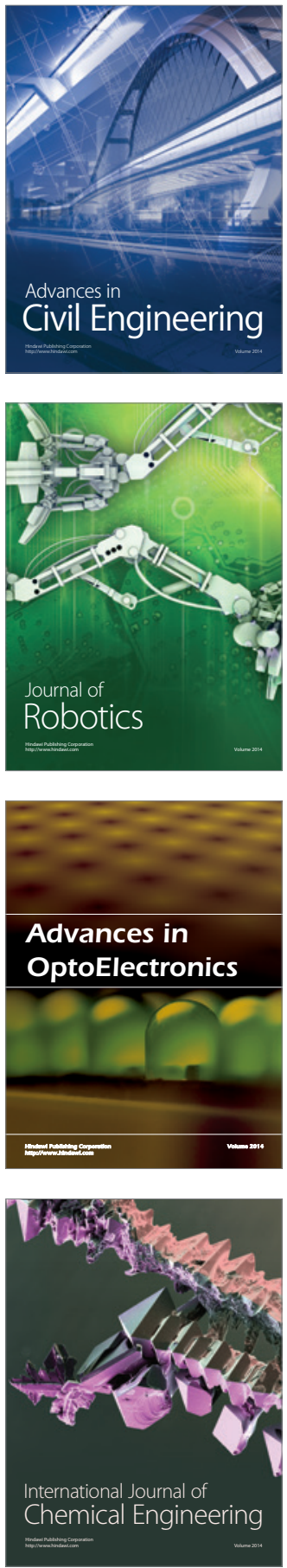

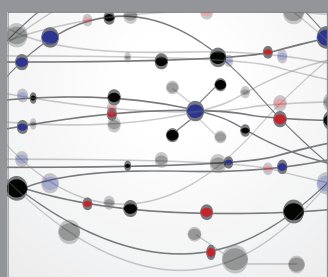

The Scientific World Journal

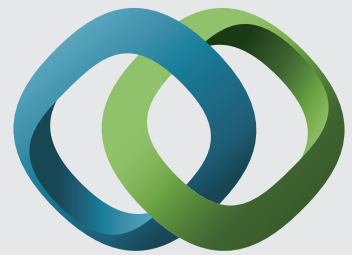

\section{Hindawi}

Submit your manuscripts at

http://www.hindawi.com
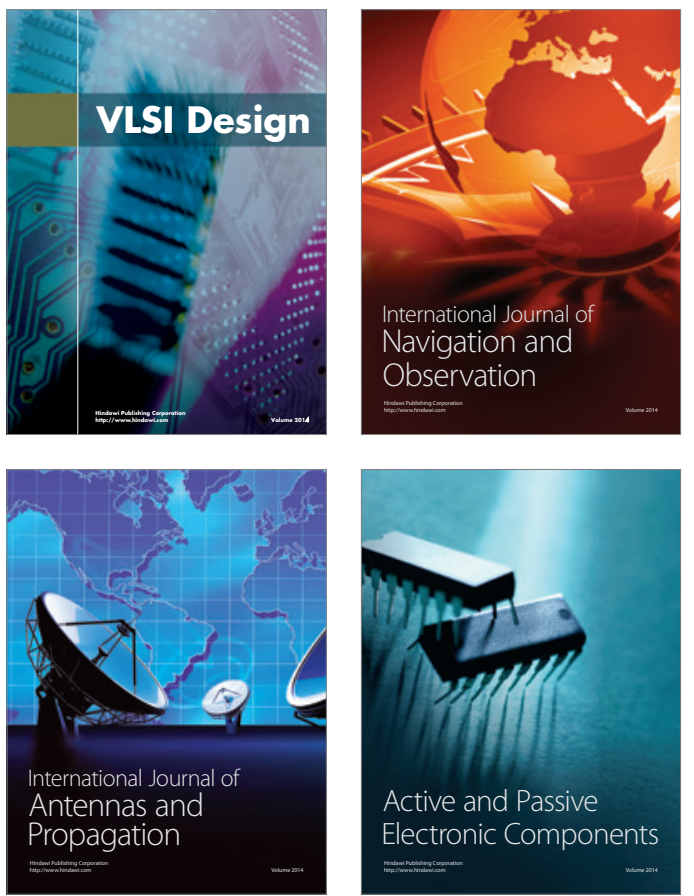
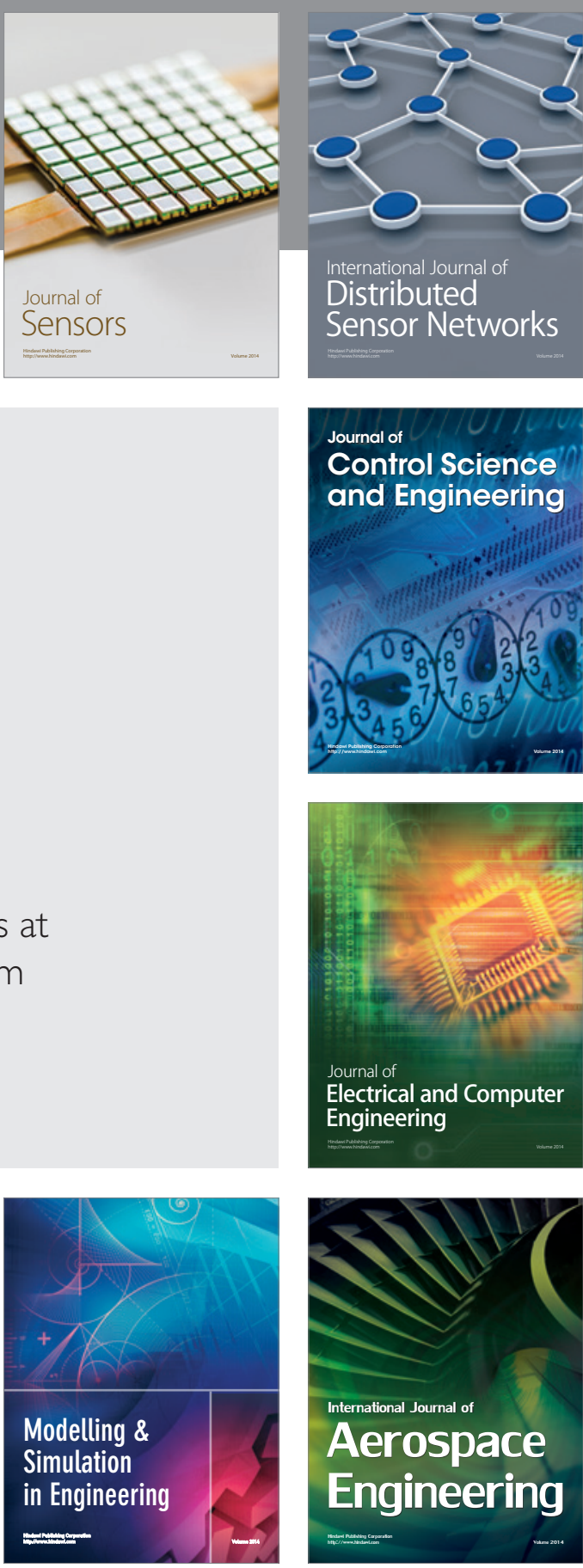

International Journal of

Distributed

Sensor Networks

Journal of

Control Science

and Engineering
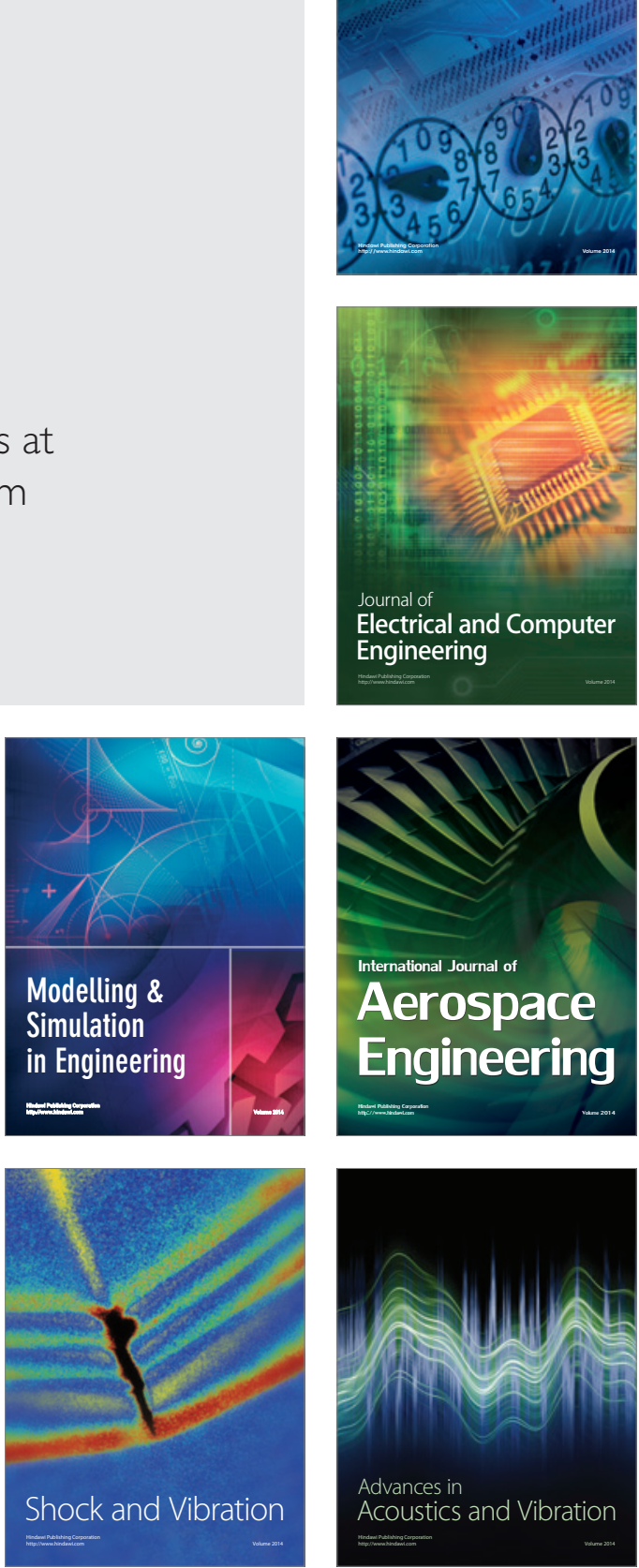